\title{
A new overview on rare earth diphenylphosphinates: Europium characteristic luminescence of low dimensional nanostructured materials
}

\author{
Luís F. Bricks Bim, Elizabeth B. Stucchi, Marco A. Cebim* \\ São Paulo State University (Unesp), Institute of Chemistry, Department of General and Inorganic Chemistry, Luminescent Materials Laboratory, Araraquara, São Paulo, \\ Brazil
}

\section{A R T I C L E I N F O}

\section{Keywords:}

Coordination compounds

Metal-organic frameworks

Coordination polymers

Nanowires

Lanthanides

Photoluminescence spectroscopy

\begin{abstract}
A B S T R A C T
Porous crystalline luminescent polymer compounds have attracted huge interest due to their supramolecular structures, aesthetically attractive structural topologies and potentialities for innovative technological applications. However, wet route precipitation or hydro/solvothermal methods may lead to the formation of highly insoluble porous coordination networks, as is true of europium diphenylphosphinates $-\left[\mathrm{Eu}(d p p)_{3}\right]_{\mathrm{n}}$. The aim of this work was to study the optical behavior and its relation to the structure of $\left[\mathrm{Eu}(d p p)_{3}\right]_{\mathrm{n}}$ complexes obtained through different synthetic approaches by precipitation: wet route (WRS), ultrasound-assisted wet route (UWRS), modulator-assisted wet route (M-WRS) and wet route synthesis with solvothermal treatment (S-WRS). These methodologies allowed to synthetize crystalline materials in which both chelate and bridged coordination modes coexist, and they were efficient for obtaining stick-shaped 1D1 nanostructured materials with well-defined optical properties. Changes in precipitation kinetics and crystalline phases formation rate led to a distribution of $\mathrm{Eu}^{3+}$ ions in higher symmetry sites (HSS). S-WRS, transforming part of the less symmetrical sites into HSS, provided a better ordering of $\left[\mathrm{Eu}(d p p)_{3}\right]_{\mathrm{n}}$. Furthermore, this is the first report of two or more symmetry sites for $\mathrm{Eu}^{3+}$ in a pure $\left[\mathrm{Eu}(d p p)_{3}\right]_{\mathrm{n}}$ matrix.
\end{abstract}

\section{Introduction}

The search for highly porous and crystalline polymer compounds has become relevant in the research around the world and has generated, in the last three decades [1], a growing interest not only in the scientific community but also in several areas of technology. Main reasons for this are due to their supramolecular structures, aesthetically attractive structural topologies and potentialities for innovative technological applications of high added value [2].

Actually, these singular compounds led to the advent of a new and important class of multifunctional porous materials called metal-organic frameworks (MOFs) [3-5], which have unique characteristics and intrinsic properties that promote them to the level of excellent candidates for the most varied applications [6].

MOFs are chemically more interesting than conventional porous inorganic materials, since they can be manipulated to give rise to modulable structures with desired topologies [7-9]. They are constructed from the connection between inorganic units with organic ligands, where the building units can be changed almost at will [10].

With such flexibility, MOFs are regarded as exceptional materials for the construction of functional entities at the interface of nanocrystalline solids, allowing the control of their properties [10].

Furthermore, allying organic linkers (that can act as bridging linkers, such as carboxylated and phosphorylated linkers) to the flexible coordination modes and the high coordination number of trivalent rare earth cations $\left(\mathrm{RE}^{3+}\right)$ is an efficient strategy to obtain porous coordination networks with channels and cavities that can be emptied or filled without collapse of the crystalline structure.

These trivalent rare earth-based MOFs $-\mathrm{RE}^{3}{ }^{+} \mathrm{MOF}-[11]$ present odd luminescent and magnetic properties. This is due to the different $\mathrm{RE}^{3+}-\mathrm{RE}^{3+}$ and/or $\mathrm{RE}^{3+}$-ligand chemical environments imposed by the coordination network, leading to several relaxation mechanisms, such as ligand- $\mathrm{RE}^{3+}$ cross relaxation and $4 \mathrm{f}-4 \mathrm{f}$ intraconfigurational transitions.

Among the several reported applications in the literature for $\mathrm{RE}^{3+} \mathrm{MOF}$, it is possible to highlight their use in the sensing of humidity, $\mathrm{pH}$, temperature and explosives $[12,13]$.

Therefore, it is of interest the rational design and synthesis of $\mathrm{RE}^{3+} \mathrm{MOFs}$, looking forward to a better understanding of their optical and structural properties, which could allow applications in an improved way with great technological power.

However, obtaining $\mathrm{RE}^{3+} \mathrm{MOF}$ by wet route precipitation or

\footnotetext{
* Corresponding author.

E-mail address: mcebim@iq.unesp.br (M.A. Cebim).
} 
hydro/solvothermal methods may lead to the formation of highly insoluble porous coordination networks in different solvents commonly used in the laboratory, either polar or non-polar.

This variant makes it difficult to obtain crystals with a long-range periodic arrangement of perfectly stacked unit cells that can be easily characterized by single crystal X-ray diffraction (SCXRD), considered one of the most powerful techniques for structural elucidation of crystalline materials [14].

Rare earth diphenylphosphinates - $\left[\operatorname{RE}(d p p)_{3}\right]_{\mathrm{n}}$, synthesized by direct reaction between a rare earth chloride $\left(\mathrm{RECl}_{3}\right)$ and diphenylphosphinic acid (Hdpp), are authentic examples that integrate this class of materials presenting very low solubilities that do not produce single crystals.

In this work, we report for the first time - to the best of our knowledge - that modifications in synthetic methods and strict control of synthesis parameters in $\left[\operatorname{RE}(d p p)_{3}\right]_{\mathrm{n}}$ preparations could lead to the formation of materials with a greater crystallinity with defined morphology and size and mainly with well-delfined optical properties, opening opportunities for future technological applications of these phosphinates in lighting, ionizing radiation detection and sensing.

To achieve that, four different synthetic approaches by precipitation were addressed: wet route (WRS), ultrasound-assisted wet route (UWRS), modulator-assisted wet route (M-WRS) and wet route synthesis with solvothermal treatment (S-WRS).

Acoustic cavitation in $\left[\operatorname{RE}(d p p)_{3}\right]_{\mathrm{n}}$ synthesis aims the design of an environment by which the intercurrence of homogeneous nucleation and a significant increase in the speed of recrystallization are prioritized when compared to the conventional methods applied in the preparation of nanostructured materials [15-18].

On the other hand, coordination modulators behave in a competitive way with the organic ligand by coordination with metallic ions present in solution, regulating nucleation and reducing crystal growth rate and avoiding precipitation of amorphous products $[10,19]$. In this way, they provide a more accurate control of the size and morphology of the crystals, allowing the formation of nanoparticles [20]. Indeed, modulation is a suitable strategy to improve the final product crystallinity and the synthesis reproducibility [21].

And last but not least, solvothermal process is useful for achieving thermodynamically stable and metastable states, contributing to the formation of new materials which cannot be easily synthesized from conventional synthetic routes [22].

\subsection{Background}

Studied since the $1970 \mathrm{~s},\left[\operatorname{RE}(d p p)_{3}\right]_{\mathrm{n}}$ are presented as peculiar and somewhat intriguing materials. They have two distinct symmetry sites for trivalent rare earth, thermal stability similar to that of inorganic phosphates and mesoporous structure with the presence of crystalline and non-crystalline domains.

In the first report of rare earth diphenylphosphinates preparation, Dunstan and Vicentini [23] proposed the general formula $\operatorname{RE}(d p p)_{3} \cdot \mathrm{n}$ $\left(\mathrm{H}_{2} \mathrm{O}\right)$ for the synthesized coordination compounds.

Bel'tyukova [24] in 1989 published the first spectroscopic study involving compounds formed by trivalent europium and diphenylphosphinate ligand reported in the literature.

Innocentini and co-workers [25] synthesized a non-hygroscopic europium diphenylphosphinate with high thermal stability in comparison with other coordination compounds and reasonable ligand-tometal energy transfer ability via antenna effect.

Stucchi [26], Scarpari [27,28] and their collaborators prepared a series of rare earth diphenylphosphinates and binary compounds, examining their optical behavior to predict some structural information.

Francisco et al. [29] suggested the presence of one or more symmetry sites for $\mathrm{RE}^{3+}$ in a europium-doped yttrium diphenylphosphinate matrix. In another study [30], applying the hydrothermal synthesis, they obtained unidimensional structures in the form of rods.
According to Abreu et al. [31,32], $\left[\operatorname{RE}(d p p)_{3}\right]$ are polycrystalline materials in a polymeric arrangement, resulting in coordination sites of different symmetries, and can be represented by $\left[\operatorname{RE}(d p p)_{3}\right]_{n}$.

Souza [33], Munhoz [34] and their co-workers have investigated the potential application of lanthanum and cerium diphenylphosphinates (and their doping) as UV absorbers.

Rosa et al. [35] examined the effect of cerium as a sensitizer and activator on the compounds $\left[\mathrm{La}(d p p)_{3}\right]: \mathrm{Eu}^{3+}$ and $[\mathrm{La}$ $\left.(d p p)_{3}\right]: \mathrm{Eu}^{3+}, \mathrm{Tb}^{3+}$ and their possible uses as emission-emitting luminescent materials of white light.

In addition, Rosa et al. [36] proposed that diphenylphosphinate coordination compounds of $\mathrm{La}^{3+}-\mathrm{Ce}^{3+}-\mathrm{Eu}^{3+} / \mathrm{La}^{3+}-\mathrm{Ce}^{3+}-\mathrm{Tb}^{3+}$ ternary systems exist as cross-linked coordination polymers, forming a binuclear system: $\left[\mathrm{RE}_{2}(d p p)_{6}\right]_{\mathrm{n}}$. They also verified that those ternary systems have an appreciable resistance to ionizing radiation.

Recently, Bim et al. [37] carried out a systematic study of trivalent rare earth diphenylphosphinates in an attempt to elucidate the structure and symmetry of the trivalent lanthanide crystallographic site, as well as the coordination mode of the $d p p^{-}$ligand to $\mathrm{RE}^{3+}$ cations.

Many gaps regarding the structure of $\left[\operatorname{RE}(d p p)_{3}\right]_{\mathrm{n}}$ are still found without complete investigation data. In previously presented works, the authors did not include details about the composition and coordination sphere of the compounds, nor did they refer to the symmetry of $\mathrm{RE}^{3+}$ crystallographic site, the coordination mode of $d p p^{-}$ligand to metal cations or thermal behavior presented by them.

Thus, a more comprehensive study of rare earth diphenylphosphinates in terms of their structures and intrinsic optical properties will provide the means to both promote them to the level of metalorganic frameworks and to suggest applications of scientific, technological and industrial interest.

\section{Experimental section}

$\left[\operatorname{RE}(d p p)_{3}\right]_{\mathrm{n}}$ synthesis was reviewed and modified from that initially proposed by Stucchi et al. [26] to more precise and controlled synthesis parameters, such as temperature and atmosphere of the reaction medium, stirring, reaction time and solvent used. It is emphasized that the authors of this paper have been working with the complete series of rare earth diphenylphosphinates $\left(\left[\mathrm{RE}(d p p)_{3}\right]_{\mathrm{n}}, \mathrm{RE}^{3+}=\mathrm{Y}^{3+}, \mathrm{La}^{3+}\right.$ through $\mathrm{Lu}^{3+}$ ); however, for the scope of this paper, we decided to focus on $\left[\mathrm{Eu}(d p p)_{3}\right]_{\mathrm{n}}$ results, addressing the intrinsic optical properties of trivalent europium ion. Purity and brands: $\mathrm{EuCl}_{3}$ solution was obtained by the stoichiometric hydrochloric acid (Sigma-Aldrich, 37\%) attack on $\mathrm{Eu}_{2} \mathrm{O}_{3}$ (Aldrich, 99.99\%) and its concentration was determined by complexation titrimetry, diphenylphosphinic acid (Aldrich, $\geq 98.0 \%$ ), methanoic acid (Sigma-Aldrich, $\geq 95 \%$ ), ethanol (Sigma-Aldrich, $\geq 99.5 \%$ ), compressed nitrogen gas (White Martins, 99.998\%).

\subsection{Wet route precipitation synthesis (WRS)}

The preparation consisted of mixing $\mathrm{EuCl}_{3}$ solution $(4.40 \mathrm{~mL}$, $0.4488 \mathrm{mmol}$ ) with ligand solution (diphenylphosphinic acid, Hdpp $0.2998 \mathrm{~g}, 1.3464 \mathrm{mmol}$ ) in 1:3 metal-to-ligand ratio. The solvent used was $40.00 \mathrm{~mL}$ of a 1:1 mixture of ethanol and distilled water. The ligand solution was placed in a three-necked round bottom flask, kept in a microprocessed hot water bath. The temperature of the reaction medium was maintained at $72 \pm 3{ }^{\circ} \mathrm{C}$ and measured by thermocouple (NTC sensor - nickel-plated brass - $\varnothing 6.35 \mathrm{~mm} / \mathrm{L}=22 \mathrm{~mm}$ ) coupled to a digital temperature controller (Ageon G101 Color). The ligand solution was subjected to constant stirring and the round bottom flask saturated with $\mathrm{N}_{2(\mathrm{~g})}$. $\mathrm{EuCl}_{3}$ solution was slowly dripped onto the ligand solution via a 10-mL burette, causing the precipitation of $\left[\mathrm{Eu}(d p p)_{3}\right]_{\mathrm{n}}$. After the addition of $\mathrm{EuCl}_{3}$ solution, the mixture (precipitate and supernatant) remained in the hot water bath under stirring for $60 \mathrm{~min}$. The flask was then removed from the system and kept under stirring for extra $30 \mathrm{~min}$. 
At the end of this process, the contents of the flask (precipitate and supernatant) were transferred to a $50-\mathrm{mL}$ centrifuge tube, remaining at rest for $24 \mathrm{~h}$. After this period, the mixture was centrifuged at $10,000 \mathrm{rpm}$ for $10 \mathrm{~min}$ (Eppendorf Centrifuge 5804R). The precipitate was separated from the supernatant and washed with the ice-cold ethanol/water (1:1) mixture, then settled in a desiccator containing silica gel for 7 days.

\subsection{Ultrasound-assisted wet route precipitation synthesis (U-WRS)}

The synthesis of ultrasound-assisted europium diphenylphosphinate was carried out in a cell disruptor (R2D091109 - UNIQUE). It consisted of mixing $\mathrm{EuCl}_{3}$ solution $(4.40 \mathrm{~mL}, 0.4488 \mathrm{mmol}$ ) with Hdpp solution $(0.2998 \mathrm{~g}, 1.346 \mathrm{mmol})$ in $1: 3$ metal-to-ligand ratio subjected to high intensity sonication. The solid ligand was placed in a three-necked round bottom flask containing $40.00 \mathrm{~mL}$ of solvent (a 1:1 mixture of ethanol and distilled water). This flask was kept immersed in a bath with water at room temperature and continuously saturated with $\mathrm{N}_{2(\mathrm{~g})}$. A titanium horn driven by a piezoelectric transducer was introduced directly into the solution through the central mouth of the round bottom flask and $20 \mathrm{kHz}$ pulses were applied for 2 min leading to complete solubilization of diphenylphosphinic acid. Keeping the pulse sequence, $\mathrm{EuCl}_{3}$ solution was slowly dripped onto $\mathrm{Hdpp}$ solution by means of a $10-\mathrm{mL}$ burette, causing the precipitation of $\left[\mathrm{Eu}(d p p)_{3}\right]_{\mathrm{n}}$. After the addition of $\mathrm{EuCl}_{3}$ solution, the mixture (precipitate and supernatant) remained under cavitation for $8 \mathrm{~min}$. At the end of this process, the contents of the flask (precipitate and supernatant) were transferred to a $50-\mathrm{mL}$ centrifuge tube, remaining at rest for $24 \mathrm{~h}$. The other procedures were identical to those described at the end of Subsection 2.1.

\subsection{Modulator-assisted wet route precipitation synthesis (M-WRS)}

For the synthesis of modulator-assisted europium diphenylphosphinate, we used a monocarboxylic acid as modulating agent, more specifically, methanoic acid. The whole procedure is similar to those described in Subsection 2.1, only adding the methanoic acid $(1.82 \mathrm{~mL}$, $44.88 \mathrm{mmol}$ ) to the flask containing the already solubilized ligand.

\subsection{Wet route precipitation synthesis with solvothermal treatment (S-WRS)}

The preparation of $\left[\mathrm{Eu}(d p p)_{3}\right]_{\mathrm{n}}$ was carried out as described in Subsection 2.1 until prior to its centrifugation. The contents of the flask (precipitate and supernatant) were transferred to a Teflon beaker, keeping $30 \%$ of its useful volume unoccupied. $\mathrm{N}_{2(\mathrm{~g})}$ was used to saturate the medium. The Teflon beaker was then introduced into a stainlesssteel reactor, arranged in a circulation oven (Model MSM 510/27/CR/ RP, Series 1105.0218 - M.S. Mistura Equipamentos para Laboratório) and subjected to controlled temperature programming: heating rate, $3.2{ }^{\circ} \mathrm{Ch}^{-1}$; landing, $180^{\circ} \mathrm{C} / 48 \mathrm{~h}$; cooling rate up to room temperature, $1.6^{\circ} \mathrm{Ch}^{-1}$. After the solvothermal treatment, the reactor contents (precipitate and supernatant) were transferred to a $50-\mathrm{mL}$ centrifuge tube, remaining at rest for $24 \mathrm{~h}$. The other procedures were identical to those described at the end of Subsection 2.1.

\subsection{Characterization}

$\left[\mathrm{Eu}(d p p)_{3}\right]_{\mathrm{n}}$ obtained through the four routes described above (Subsections 2.1-2.4) have been subjected to several structural and spectroscopic characterization techniques. Elemental analysis was performed on a Perkin Elmer 2400 Series II CHNS/O Elemental Analyzer. Analysis based on X-ray diffraction was carried out on Siemmens diffractometer with copper rotational anode using $\mathrm{Cu}-\mathrm{Ka} 1$ radiation $(1.5418 \AA)$ and graphite curved monochromator. [Eu $\left.(d p p)_{3}\right]_{\mathrm{n}}$ morphology and size were observed by using scanning electron microscope (SEM) JEOL JSM7500F equipped with a field emission gun (FEG)

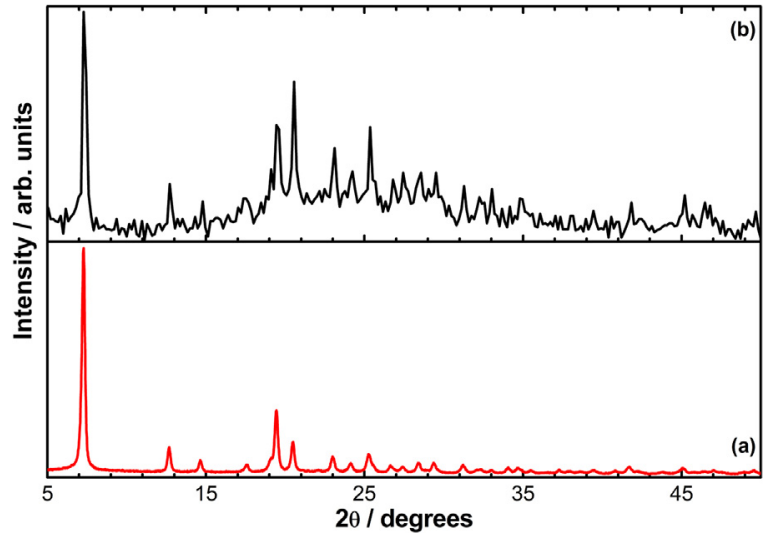

Fig. 1. (a) XRD pattern of $\left[\mathrm{Eu}(d p p)_{3}\right]_{\mathrm{n}}$ synthesized by WRS (Subsection 2.1) and (b) XRD pattern of $\left[\mathrm{Eu}(d p p)_{3}\right]_{\mathrm{n}}$ synthesized by conventional WRS (provided by reference [26]).

operated at $2.00 \mathrm{kV}$; particle counting and determination of their dimensions were performed by inspection with the aid of a image processing and analysis software in Java, ImageJ. Photoluminescence emission and excitation spectra were obtained using a Horiba Jobin Yvon spectrofluorimeter, model Fluorolog-3, and registered in UV-Vis region using a photomultiplier Horiba Jobin Yvon R928 and xenon lamp (ozone free); emission spectra were collected in triplicate and submitted to one-way ANOVA (analysis of variance) with post-hoc Tukey HSD (honestly significant difference) test. Vibrational spectra were obtained with BRUKER Fourier-transform infrared spectrophotometer - VERTEX 70 with DLaTGS detector, using an attenuated total reflectance (ATR) accessory.

\section{Results and discussion}

The new methodologies (Subsections 2.1-2.4) adopted for [Eu $\left.(d p p)_{3}\right]_{\mathrm{n}}$ preparation had positive impact on the precipitation of the metal complexes, providing controlled growth of materials remarkably more crystalline and organized than those previously reported in the literature [26,27,30,36] (Fig. 1).

Independently of the adopted synthetic route, the precipitations were stoichiometric; the overall reactions yields were always higher than $90 \%$ and the losses are related to the processes of washing, transference and maceration of precipitates. Elemental analyzes of [Eu $\left.(d p p)_{3}\right]_{\mathrm{n}}$ synthesized by WRS, U-WRS, M-WRS and S-WRS provided carbon, hydrogen and nitrogen (adsorbed in the pores of the structures) contents ranging between $54.84-55.10 \%, 3.66-3.78 \%$ and $2.12-2.82 \%$, respectively.

XRD pattern of WRS $\left[\mathrm{Eu}(d p p)_{3}\right]_{\mathrm{n}}$ is shown in Fig. 1(a) and should be regarded as representative of whole synthesized series through the synthetic modifications proposed by the authors of this paper; U-WRS, M-WRS and S-WRS XRD patterns are available in Supplementary material (Fig. S1). Thus, rare earth diphenylphosphinates are found to have the same diffraction pattern, suggesting that $\left[\operatorname{RE}(d p p)_{3}\right]_{\mathrm{n}}$ are isostructural. The presence of an intense low-angle diffraction, close to seven $2 \theta$ /degrees (interplanar spacing $d \sim 12 \AA$ ), is also repeated in all the synthesized coordination compounds. These results are similar to the behavior shown by MOFs [38] and corroborate those described in the literature [26,28,29,32].

However, the results revealed that a meticulous control of the reaction medium temperature and atmosphere was able to support the crystalline organization of the materials, significantly increasing the signal-to-noise ratio of the diffraction (Fig. 1).

When comparing interplanar distances of $\left[\mathrm{Eu}(d p p)_{3}\right]_{\mathrm{n}}$ reflections with those reported by Stucchi et al. (Table 1), small displacements in d (A) values are observed, suggesting possible modifications in crystalline 
Table 1

Crystallographic data (relative intensities and interplanar distance) of $\left[\mathrm{Eu}(d p p)_{3}\right]_{\mathrm{n}}$ obtained by different synthetic routes.

\begin{tabular}{|c|c|c|c|c|c|c|c|c|c|c|c|c|c|c|}
\hline \multicolumn{3}{|l|}{ WRS } & \multicolumn{3}{|l|}{ U-WRS } & \multicolumn{3}{|l|}{ M-WRS } & \multicolumn{3}{|l|}{ S-WRS } & \multicolumn{3}{|c|}{$\begin{array}{l}\text { Conventional WRS (provided by reference } \\
{[26] \text { ) }}\end{array}$} \\
\hline $2 \theta$ (degrees) & $\mathrm{I} / \mathrm{I}_{0}(\%)$ & $\mathrm{d}(\AA)$ & $2 \theta$ (degrees) & $\mathrm{I} / \mathrm{I}_{0}(\%)$ & $\mathrm{d}(\AA)$ & $2 \theta$ (degrees) & $\mathrm{I} / \mathrm{I}_{0}(\%)$ & d (A) & $2 \theta$ (degrees) & $\mathrm{I} / \mathrm{I}_{0}(\%)$ & d (̊) & $2 \theta$ (degrees) & $\mathrm{I} / \mathrm{I}_{0}(\%)$ & $\mathrm{d}(\AA)$ \\
\hline 7.28 & 100 & 12.14 & 7.28 & 100 & 12.14 & 7.28 & 100 & 12.14 & 7.24 & 100 & 12.21 & 7.28 & 100 & 12.14 \\
\hline 12.68 & 13 & 6.98 & 12.68 & 14 & 6.98 & 12.66 & 12 & 6.99 & 12.64 & 13 & 7.00 & 12.72 & 28 & 6.96 \\
\hline 14.64 & 7 & 6.05 & 14.64 & 7 & 6.05 & 14.66 & 7 & 6.04 & 14.60 & 7 & 6.07 & 14.80 & 21 & 5.99 \\
\hline 17.62 & 5 & 5.03 & 17.60 & 7 & 5.04 & 17.62 & 5 & 5.03 & 17.46 & 4 & 5.08 & 17.36 & 22 & 5.11 \\
\hline 19.44 & 29 & 4.57 & 19.44 & 32 & 4.57 & 19.44 & 29 & 4.57 & 19.40 & 31 & 4.58 & 19.44 & 53 & 4.57 \\
\hline 20.50 & 15 & 4.33 & 20.48 & 19 & 4.34 & 20.50 & 12 & 4.33 & 20.44 & 8 & 4.34 & 20.56 & 71 & 4.32 \\
\hline 22.98 & 9 & 3.87 & 23.04 & 10 & 3.86 & 23.00 & 7 & 3.87 & 22.96 & 6 & 3.87 & 23.12 & 43 & 3.85 \\
\hline 24.14 & 6 & 3.69 & 24.10 & 7 & 3.69 & 24.14 & 5 & 3.69 & 24.08 & 5 & 3.70 & 24.24 & 33 & 3.67 \\
\hline 25.26 & 10 & 3.53 & 25.24 & 12 & 3.53 & 25.26 & 9 & 3.53 & 25.20 & 8 & 3.53 & 25.36 & 52 & 3.51 \\
\hline
\end{tabular}

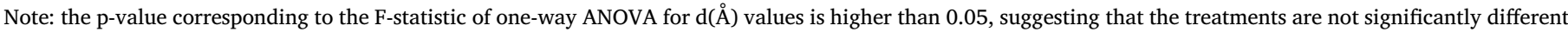
for that level of significance.

structure of these coordination compounds. These modifications must be related to the fact that precipitation kinetics of $\left[\mathrm{Eu}(d p p)_{3}\right]_{\mathrm{n}}$ are slower in the new methodologies proposed in Subsections 2.1-2.4, which allows the crystalline structure to grow more orderly.

The formation of $\left[\mathrm{Eu}(d p p)_{3}\right]_{\mathrm{n}}$, synthesized by the different routes, was also confirmed by displacements of $v\left(\mathrm{POO}^{-}\right)_{\text {ass. }}$ and $\mathrm{v}\left(\mathrm{POO}^{-}\right)_{\mathrm{s}}$. stretching bands of the coordination compounds in relation to $v(P=O)$ and $\mathrm{v}(\mathrm{PO}[\mathrm{H}])$ stretches of the ligand, respectively, which confirm that the oxygen of the phosphinate group has been coordinated to $\mathrm{RE}^{3+}$ (Table 2).

Coordination systematic was verified by comparing $v\left(\mathrm{POO}^{-}\right)_{\text {ass. }}$ and $v\left(\mathrm{POO}^{-}\right)_{\text {s. }}$ of $\left[\mathrm{Eu}(d p p)_{3}\right]_{\mathrm{n}}$ with respect to the same vibrational modes present in $\mathrm{Na}(d p p)$ and $\mathrm{NH}_{4}(d p p)$ ionic compounds (Table 3). This determined coordination systematic follows trends similar to carboxylates coordination modes in metal cations and it is based on the values presented by the $\Delta v\left(\mathrm{POO}^{-}\right)=v\left(\mathrm{POO}^{-}\right)_{\text {ass. }}-\mathrm{v}\left(\mathrm{POO}^{-}\right)_{\text {s. }}$ ratio of the coordination compounds (CC) and ionic compounds (IC) [44]. For IC, $v$ $\left(\mathrm{POO}^{-}\right)_{\text {ass. }}=1163 \mathrm{~cm}^{-1}$ and $v\left(\mathrm{POO}^{-}\right)_{\mathrm{s.}}=1069 \mathrm{~cm}^{-1}$.

Two distinct situations were observed: (i) $\Delta v\left(\mathrm{POO}^{-}\right)_{\mathrm{CC}} \approx \Delta v$ $\left(\mathrm{POO}^{-}\right)_{\mathrm{IC}}$, with a bridging metal-ligand coordination and (ii) $\Delta v$ $\left(\mathrm{POO}^{-}\right)_{\mathrm{CC}} \| \Delta v\left(\mathrm{POO}^{-}\right)_{\mathrm{IC}}$ referring to a chelating metal-ligand coordination. A $10 \%$ margin of $\Delta v\left(\mathrm{POO}^{-}\right)_{\text {IC }}$ value was used to determine the ranges related to coordination modes. Thus, it may be considered that $\left[\mathrm{Eu}(d p p)_{3}\right]_{\mathrm{n}}$ are compounds in which two distinct forms of coordination coexist, both chelate and bridged. The visualization of such coordination modes can be better understood with the aid of Fig. S2., available in Supplementary material.

Regarding morphology, Francisco et al. [30] observed that [Y $\left.(d p p)_{3}\right]: \mathrm{Eu}^{3+}(1 \%, 5 \%$ and $10 \%)$ obtained by solvothermal synthesis in single ampoules and under acetic medium $\left(180^{\circ} \mathrm{C} / 24 \mathrm{~h}\right)$ were in agglomerates form with trend to originate stick-shaped particles, which was not verified in conventional WRS. In this case, yttrium diphenylphosphinates appeared as small particles in an agglomerate with no
Table 3

FTIR $-\Delta \mathrm{v}\left(\mathrm{POO}^{-}\right)$displacements of $\left[\mathrm{Eu}(d p p)_{3}\right]_{\mathrm{n}}$ and ionic compounds.

\begin{tabular}{lllll}
\hline Synthetic route & Compound & \multicolumn{2}{l}{$\Delta \mathbf{U}\left(\mathbf{P O O}^{-}\right)$} & \\
\hline WRS & {$\left[\mathrm{Eu}(d p p)_{3}\right]_{\mathrm{n}}$} & 80 & 86 & 91 \\
U-WRS & & 80 & 86 & 92 \\
M-WRS & & 80 & 86 & 91 \\
S-WRS & & 80 & 86 & 91 \\
IC & $\mathrm{Na}(d p p)$ & 93 & & \\
& $\mathrm{NH}_{4}(d p p)$ & 94 & & \\
& & &
\end{tabular}

Units: $\mathrm{cm}^{-1}$.

defined shape. The results of Rosa et al. [36] corroborate those described by Francisco et al. [30], whereby diphenylphosphinates complexes of $\mathrm{La}^{3+}-\mathrm{Ce}^{3+}-\mathrm{Eu}^{3+} / \mathrm{La}^{3+}-\mathrm{Ce}^{3+}-\mathrm{Tb}^{3+}$ ternary systems prepared by precipitation are presented as agglomerates, with no defined shape.

Through the synthetic approaches described in Subsections 2.1-2.4, excellent improvements in morphological characteristics of $\left[\mathrm{Eu}(d p p)_{3}\right]_{\mathrm{n}}$ were obtained, verified by SEM-FEG photomicrographs (Fig. 2).

The rigorous control of WRS, U-WRS, M-WRS and S-WRS synthesis parameters for $\left[\mathrm{Eu}(d p p)_{3}\right]_{\mathrm{n}}$ preparation promoted its organized growth as 1D1 nanostructured materials ( $k \mathrm{Dlmn}$ notation for nanostructures) [45] in stick-shaped particles. Dimensions (length and diameter) of [Eu $\left.(d p p)_{3}\right]_{\mathrm{n}}$ particles obtained by those approaches can be found in Table 4 .

For WRS, particles of $702( \pm 449) \mathrm{nm}$ average width (Fig. 3.(a)) and $46.04( \pm 10.83) \mathrm{nm}$ average diameter (Fig. 3.(b)) are verified. It was observed, however, that those particles were distributed in two distinct groups: those that nucleated within the liquid and grew and others that did not evolve with the addition of more units to the crystallization nucleus. These smaller, less dense particles were scattered over the entire surface of the aggregate, while the longer ones $(>1,500 \mathrm{~nm}$ ), intricate to each other, were covered up by those ones. The high intensity sonication employed in U-WRS approach caused

Table 2

FTIR - Main absorptions and their respective attributions for $\left[\mathrm{Eu}(d p p)_{3}\right]_{\mathrm{n}}$ obtained by different synthetic routes and for Hdpp ligand.

\begin{tabular}{|c|c|c|c|c|c|}
\hline Attribution & \multicolumn{4}{|l|}{$\left[\mathrm{Eu}(d p p)_{3}\right]_{\mathrm{n}}$} & Hdpp \\
\hline$v(\mathrm{CH})_{\mathrm{sp}}^{2}$ & 3012-3093 & 3011-3092 & 3012-3093 & 3011-3092 & $3056-3076$ \\
\hline $\mathrm{v}\left(\mathrm{POO}^{-}\right)_{\text {ass. }}$ & $1130 ; 1136 ; 1141$ & $1130 ; 1136 ; 1142$ & $1130 ; 1136 ; 1141$ & $1130 ; 1136 ; 1141$ & - \\
\hline $\mathrm{v}\left(\mathrm{POO}^{-}\right)_{\mathrm{s}}$ & 1050 & 1050 & 1050 & 1050 & - \\
\hline$v(\mathrm{P}-\mathrm{O})_{\text {ass. }}$ & 1022 & 1022 & 1022 & 1022 & 1025 \\
\hline
\end{tabular}

Units: $\mathrm{cm}^{-1}$. Ref. [39-43]. 


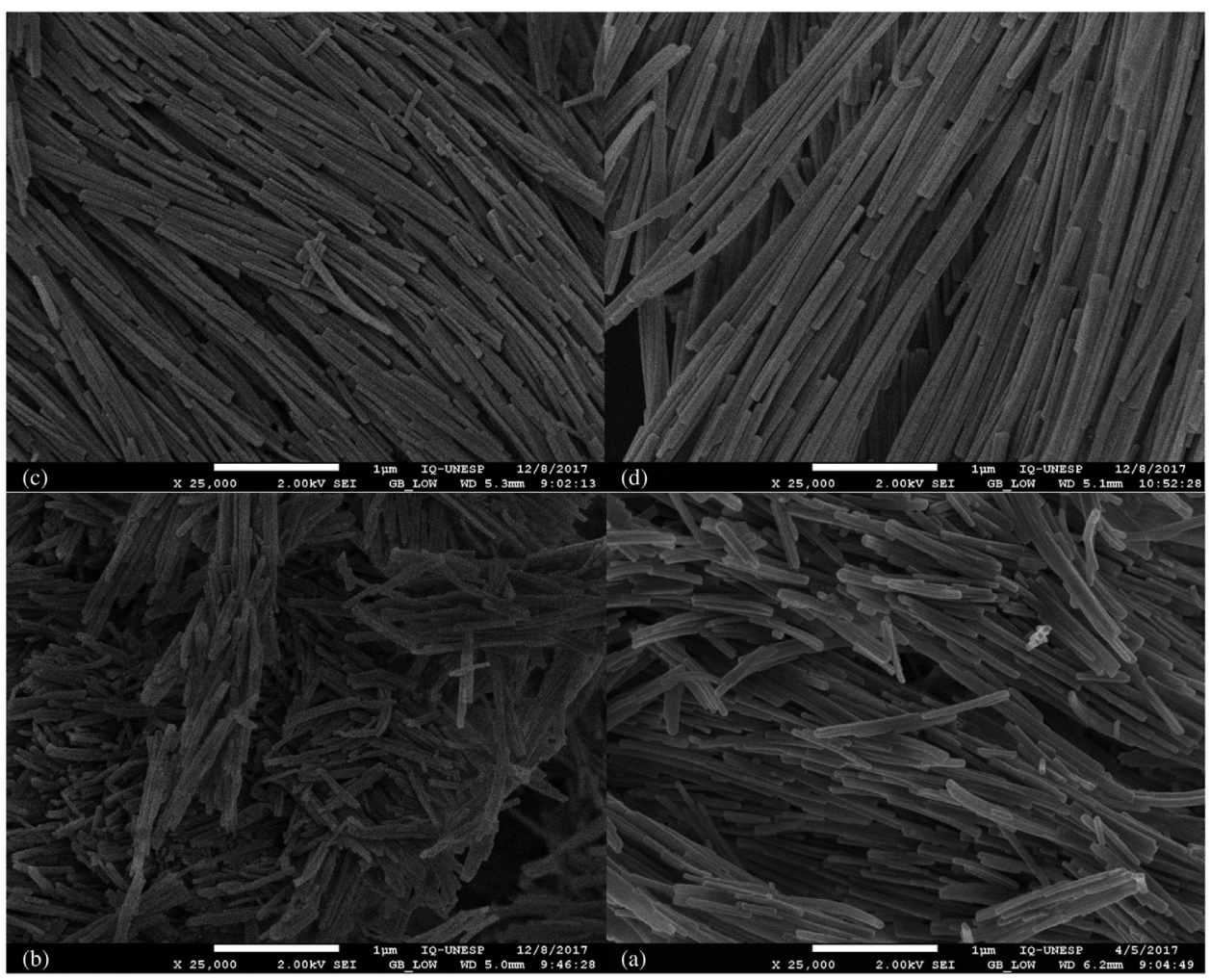

Fig. 2. SEM-FEG photomicrographs @ 25,000 $\times$ of (a) WRS $\left[\operatorname{Eu}(d p p)_{3}\right]_{\mathrm{n}}$, (b) U-WRS $\left[\operatorname{Eu}(d p p)_{3}\right]_{\mathrm{n}}$, (c) M-WRS $\left[\operatorname{Eu}(d p p)_{3}\right]_{\mathrm{n}}$, (d) S-WRS $\left[\mathrm{Eu}(d p p)_{3}\right]_{\mathrm{n}}$. Note: other photomicrographs are available in Supplementary material (Fig. S3).

Table 4

Dimensions (length and diameter) of $\left[\mathrm{Eu}(d p p)_{3}\right]_{\mathrm{n}}$ particles obtained by different synthetic routes.

\begin{tabular}{lllll}
\hline Synthetic route & $\boldsymbol{n}$ & length / nm & $\boldsymbol{n}$ & diameter / nm \\
\hline WRS & 500 & $702( \pm 449)$ & 100 & $46.04( \pm 10.83)$ \\
U-WRS & 100 & $450( \pm 197)$ & 100 & $45.09( \pm 07.08)$ \\
M-WRS & 100 & $1,580( \pm 730)$ & 100 & $39.49( \pm 09.30)$ \\
S-WRS & 100 & $>>1,000(1,000-10,000)$ & 100 & $63.10( \pm 17.34)$
\end{tabular}

Note: length and diameter are shown as the mean \pm standard deviation, except for S-WRS particles length given the difficulty in counting intact particles due to their interlacing (see Fig. S3. - Supplementary material).

damage to the crystalline structures and allowed the random breaking of the stick-shaped particles, decreasing their lengths by approximately $36 \%$ compared to those obtained via WRS, while preserving the diameters.

On the other hand, the use of the synthesis modulating agent provided a better kinetic control of nucleation. Thus, it allowed considerable elongation of the particles by reducing the crystal growth rate.

The solvothermal treatment, for providing dynamic conditions capable to dissolve and recrystallize materials that are relatively insoluble under ordinary conditions, was the approach that best managed to lengthen the 1D1 stick-shaped particles. In fact, particles 14 times longer than those obtained by WRS are observed, maintaining preserved their diameters in the range of $45-80 \mathrm{~nm}$.

Solid state photoluminescence properties of WRS, U-WRS, M-WRS and S-WRS $\left[\mathrm{Eu}(d p p)_{3}\right]_{\mathrm{n}}$ were investigated by $77 \mathrm{~K}-\mathrm{PLS}$. All excitation (EX) spectra were obtained by monitoring $\mathrm{Eu}^{3+}{ }^{5} \mathrm{D}_{0} \rightarrow{ }^{7} \mathrm{~F}_{1}$ transition, through which it is possible to observe (i) a broad and intense band related to ${ }^{1} \mathrm{~A}_{1 \mathrm{~g}} \rightarrow{ }^{1} \mathrm{~B}_{2 \mathrm{u}}$ transitions of $\mathrm{Ph}\left(\pi-\pi^{*}\right)$ system always around $270 \mathrm{~nm}$ and (ii) characteristic bands of $\mathrm{Eu}^{3+}$ between 310 and $500 \mathrm{~nm}$ referring to electronic transitions of the ground state ${ }^{7} \mathrm{~F}_{0}$ to various ${ }^{2 S}+1 L_{J}$ excited states, of which the bands close to 391 and $463 \mathrm{~nm}$ refer to $\mathrm{Eu}^{3+} 4 \mathrm{f}^{6}$ intra shell ${ }^{7} \mathrm{~F}_{0} \rightarrow{ }^{5} \mathrm{~L}_{6}$ and ${ }^{7} \mathrm{~F}_{0} \rightarrow{ }^{5} \mathrm{D}_{2}$ transitions,
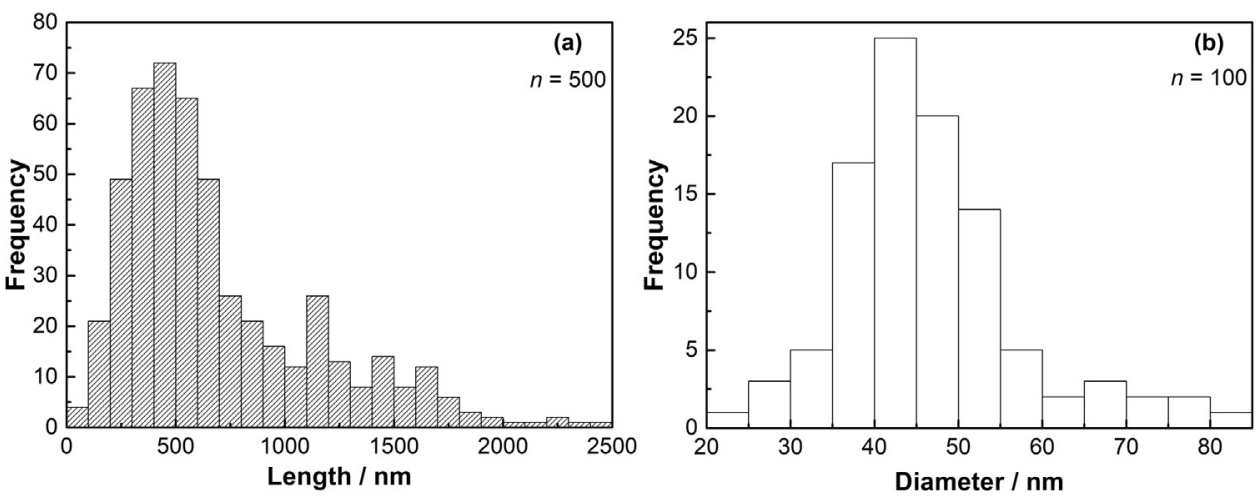

Fig. 3. Statistical distribution of WRS $\left[\mathrm{Eu}(d p p)_{3}\right]_{\mathrm{n}}$ particles dimensions: (a) length and (b) diameter. 
Table 5

Integrated intensity ratio (R) $\mathrm{I}\left({ }^{5} \mathrm{D}_{0} \rightarrow{ }^{7} \mathrm{~F}_{2}\right) / \mathrm{I}\left({ }^{5} \mathrm{D}_{0} \rightarrow{ }^{7} \mathrm{~F}_{1}\right)$.

\begin{tabular}{|c|c|c|c|c|c|c|}
\hline Synthetic route & $\lambda_{\text {exc }}$ (ligand) & $\mathbf{I}_{0-2} / \mathbf{I}_{0-1}$ & $\lambda_{\text {exc }}\left({ }^{7} \mathrm{~F}_{0} \rightarrow{ }^{5} \mathrm{~L}_{6}\right)$ & $\mathbf{I}_{0-2} / \mathbf{I}_{0-1}$ & $\lambda_{\text {exc }}\left({ }^{7} \mathrm{~F}_{0} \rightarrow{ }^{5} \mathrm{D}_{2}\right)$ & $I_{0-2} / I_{0-1}$ \\
\hline WRS & 270.0 & $0.676^{\mathrm{bA}} \pm 0.070$ & 391.4 & $0.621^{\mathrm{bA}} \pm 0.026$ & 463.4 & $1.246^{\mathrm{aA}} \pm 0.023$ \\
\hline U-WRS & 268.4 & $0.564^{\mathrm{bAB}} \pm 0.060$ & 390.8 & $0.681^{\mathrm{bA}} \pm 0.069$ & 462.8 & $1.064^{\mathrm{aBC}} \pm 0.034$ \\
\hline M-WRS & 270.0 & $0.593^{\mathrm{bAB}} \pm 0.051$ & 391.8 & $0.640^{\mathrm{bA}} \pm 0.016$ & 463.8 & $1.148^{\mathrm{aAC}} \pm 0.059$ \\
\hline S-WRS & 269.0 & $0.428^{\mathrm{cB}} \pm 0.029$ & 391.4 & $0.668^{\mathrm{bA}} \pm 0.055$ & 463.4 & $0.840^{\mathrm{aD}} \pm 0.047$ \\
\hline
\end{tabular}

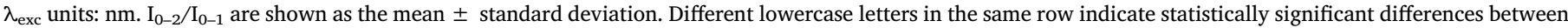

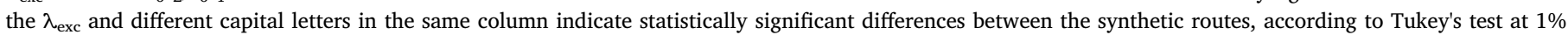
significance level. Other statistical data can be found in Supplementary material (Table S1. and Table S2.).

respectively. From emission (EM) spectra it was possible to verify relaxations of the first $\mathrm{Eu}^{3+}$ excited state, ${ }^{5} \mathrm{D}_{0}$, to the first five levels of ${ }^{7} \mathrm{~F}_{\mathrm{J}}$; it was also notable that the relative intensities of the emission spectrum bands have strong dependence on the excitation wavelength $\left(\lambda_{\text {exc }}\right)$ and that these bands undergo influence of the aromatic ringphosphoryl conjugate system excitation band up to $421 \mathrm{~nm}$. Bands from this wavelength could be basically assigned to $\mathrm{Eu}^{3+}$.

$\mathrm{Eu}^{3+}{ }^{5} \mathrm{D}_{0} \rightarrow{ }^{7} \mathrm{~F}_{1}(0-1)$ transition follows magnetic dipole rules, which makes it extremely independent of $\mathrm{Eu}^{3+}$ chemical environment [46]. However, the intensity of this transition can be identified to be constant if considered its total integrated intensity. On the other hand, $\mathrm{Eu}^{3+}{ }^{5} \mathrm{D}_{0} \rightarrow{ }^{7} \mathrm{~F}_{2}(0-2)$ transition, governed by electric dipole mechanism, is known to be hypersensitive to the chemical environment occupied by $\mathrm{Eu}^{3+}$ and the nature of the ligands; its intensity is proportional to Judd-Ofelt $\Omega_{2}$ parameter [47].

Whereas there are no modifications in ligand compositions and no substantial modifications at the metal-ligand bonding distances, we can use the ratio $(R)$ between the integrated intensities of $0-2$ and $0-1$ transitions as evidence of the existence of more than one type of symmetry site occupied by $\mathrm{Eu}^{3+}$ (Table 5). However, it is important to clarify that the ratio $\mathrm{R}$ is dependent on factors beyond the point symmetry of $\mathrm{Eu}^{3+}$ ion, such as the coordination polyhedron structure [48].

The EM and EX spectra for WRS $\left[\mathrm{Eu}(d p p)_{3}\right]_{\mathrm{n}}$ are shown in Fig. 4. In the EM spectrum (Fig. 4.(b)), we found two distinct situations: (i) when the excitation is centered on the ligand $-{ }^{1} \mathrm{~A}_{1 \mathrm{~g}} \rightarrow{ }^{1} \mathrm{~B}_{2 \mathrm{u}}$ transitions of $\mathrm{Ph}$ $\left(\pi-\pi^{*}\right)$ system - or the $\mathrm{Eu}^{3+}{ }^{7} \mathrm{~F}_{0} \rightarrow{ }^{5} \mathrm{~L}_{6}$ transition, there is predilection for symmetric sites over the lower symmetry ones, i.e. the symmetric sites contribute preferentially to the $\mathrm{Eu}^{3+}$ emission and (ii) the excitation in $\mathrm{Eu}^{3+}{ }^{3} \mathrm{~F}_{0} \rightarrow{ }^{5} \mathrm{D}_{2}$ intraconfigurational transition increases the contribution of lower symmetry sites for the intensity of EM spectrum bands. It is important to emphasize that the $\mathrm{Eu}^{3+}{ }^{3} \mathrm{~F}_{0} \rightarrow{ }^{5} \mathrm{~L}_{6}$ transition remains sensitive to the electronic transition of the ligand whereas when the excitation is centered on $\mathrm{Eu}^{3+}{ }^{7} \mathrm{~F}_{0} \rightarrow{ }^{5} \mathrm{D}_{2}$ transition that influence is practically eliminated.

U-WRS, M-WRS and S-WRS methodologies provided a homogeneous nucleation and a controlled recrystallization rate for $\left[\mathrm{Eu}(d p p)_{3}\right]_{\mathrm{n}}$ preparations, leading to a significant increase in the crystallinity of the material and an improvement in its morphological quality. Thereby, changes in precipitation kinetics and crystalline phases formation rate generated a distribution of $\mathrm{Eu}^{3+}$ ions in higher symmetry sites (HSS), so that the contribution of the lower symmetry sites never became equal to or greater than that observed in WRS methodology.

S-WRS provided a better ordering of $\left[\mathrm{Eu}(d p p)_{3}\right]_{\mathrm{n}}$ structure by facilitating the interaction between the reactional components, achieving thermodynamically stable and metastable states and thus contributing to the formation of new materials which could not be easily synthesized from conventional synthetic routes. This synthetic approach made it possible to significantly reduce the contribution of the less symmetrical site (LSS). In fact, this LSS contribution to $\mathrm{Eu}^{3+}$ emission never becomes preponderant, not even when the excitation at $\mathrm{Eu}^{3+}{ }^{7} \mathrm{~F}_{0} \rightarrow{ }^{5} \mathrm{D}_{2}$ transition (Fig. 5).

It is known that previous studies $[28,29,32]$ have already pointed to the possibility of $\mathrm{Eu}^{3+}$ occupying more than one symmetry site in yttrium, lanthanum and gadolinium diphenylphosphinates matrices doped with trivalent europium. However, it is the first time that the existence of at least two symmetry sites is verified in a pure europium diphenylphosphinate matrix - $\left[\mathrm{Eu}(d p p)_{3}\right]_{\mathrm{n}}$ synthesized by different methodologies.

\section{Conclusions}

The new methodologies proposed in this work for $\left[\mathrm{Eu}(d p p)_{3}\right]_{\mathrm{n}}$ synthesis rendered crystalline and organized materials as a result of meticulous control of the synthesis parameters. Actually, such strict control led to the formation of 1D1 nanostructured materials in stickshaped particles. In addition, comparisons of $\mathrm{v}\left(\mathrm{POO}^{-}\right)_{\text {ass. }}$ and $\mathrm{v}\left(\mathrm{POO}^{-}\right)_{\mathrm{s} \text {. }}$ stretches present in $\left[\mathrm{Eu}(d p p)_{3}\right]_{\mathrm{n}}, \mathrm{Na}(d p p)$ and $\mathrm{NH}_{4}(d p p)$ made it possible to determine that $\left[\mathrm{Eu}(d p p)_{3}\right]_{\mathrm{n}}$ are compounds in which chelate and bridged coordination modes coexist. The relative intensities of EM spectrum bands have strong dependence on the excitation wavelength. In an unprecedented way, we could observe, through the integrated intensity ratio (R) $\mathrm{I}\left({ }^{5} \mathrm{D}_{0} \rightarrow{ }^{7} \mathrm{~F}_{2}\right) / \mathrm{I}\left({ }^{5} \mathrm{D}_{0} \rightarrow{ }^{7} \mathrm{~F}_{1}\right)$, the existence of more than one symmetry site type occupied by $\mathrm{Eu}^{3+}$ in a pure europium diphenylphosphinate matrix. We were also able to show that U-WRS,
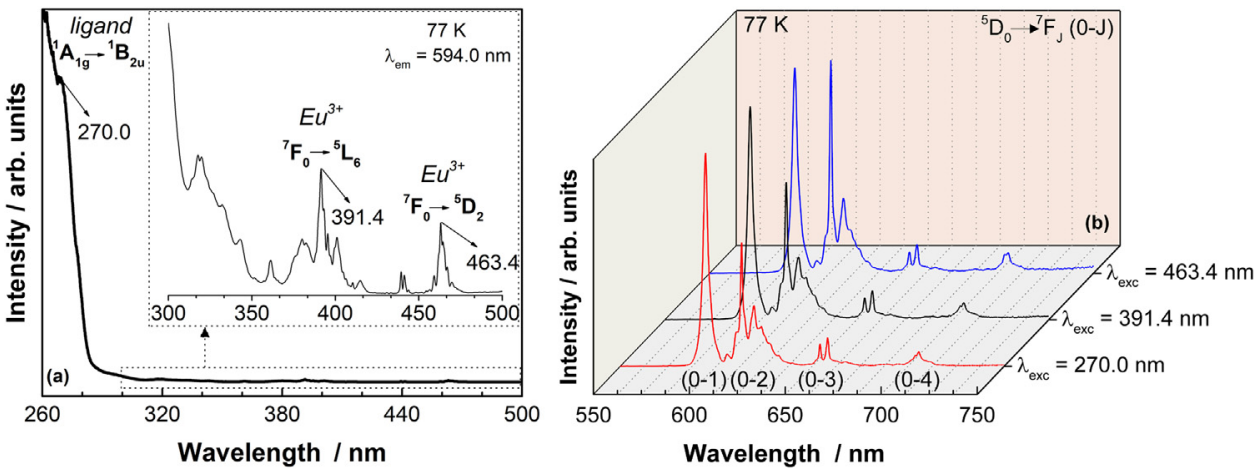

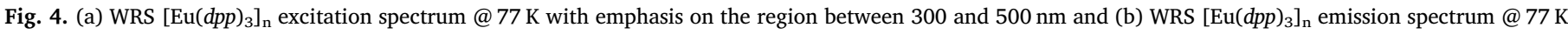
with selective excitations. 

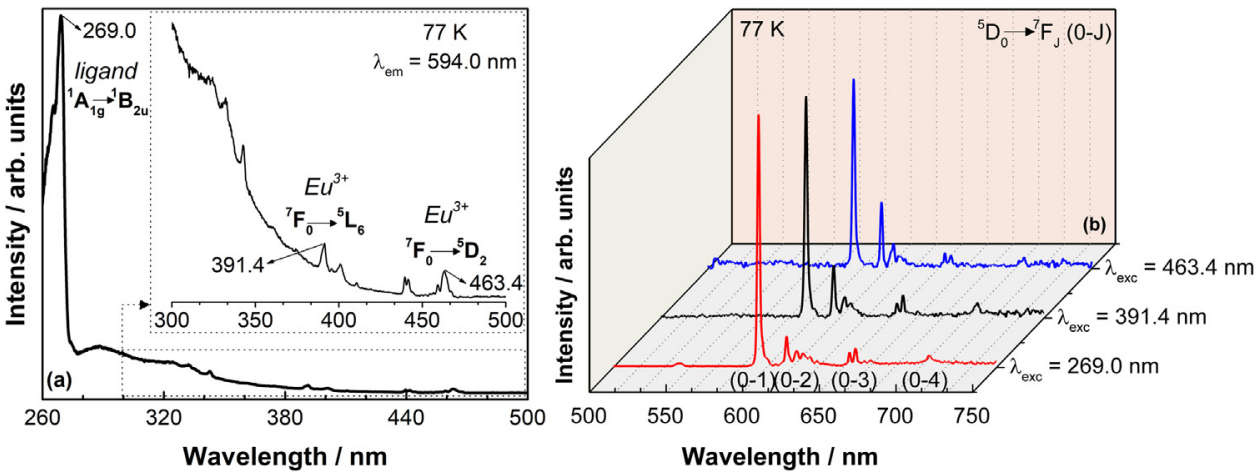

Fig. 5. (a) S-WRS $\left[\mathrm{Eu}(d p p)_{3}\right]_{\mathrm{n}}$ excitation spectrum @ $77 \mathrm{~K}$ with emphasis on the region between 300 and $500 \mathrm{~nm}$ and (b) S-WRS [Eu(dpp) $\left.]_{3}\right]_{\mathrm{n}}$ emission spectrum @ $77 \mathrm{~K}$ with selective excitations.

M-WRS and S-WRS methodologies provided a distribution of $\mathrm{Eu}^{3+}$ ions in higher symmetry sites (HSS); the contribution of the sites of lower symmetry to the emission never became equal to or greater than that observed in WRS. As a matter of fact, S-WRS was the approach that best ordered $\left[\mathrm{Eu}(d p p)_{3}\right]_{\mathrm{n}}$ structure, reducing significantly the contribution of the less symmetrical site (LSS).

\section{Acknowledgments}

This work was financially supported by CNPq and CAPES - Brazilian Agencies.

\section{Appendix A. Supporting information}

Supplementary data associated with this article can be found in the online version at https://doi.org/10.1016/j.jlumin.2018.06.040.

\section{References}

[1] S.R. Batten, N.R. Champness, X.-M. Chen, J. Garcia-Martinez, S. Kitagawa, L. Öhrström, M. O'Keeffe, M. Paik Suh, J. Reedijk, Terminology of metal-organic frameworks and coordination polymers (IUPAC Recommendations 2013), Pure Appl. Chem. 85 (2013) 1715-1724, http://dx.doi.org/10.1351/PAC-REC-12-11-20.

[2] R. Ricco, C. Pfeiffer, K. Sumida, C.J. Sumby, P. Falcaro, S. Furukawa,

N.R. Champness, C.J. Doonan, Emerging applications of metal-organic frameworks, CrystEngComm 18 (2016) 6532-6542, http://dx.doi.org/10.1039/C6CE01030J.

[3] H.-C. Zhou, J.R. Long, O.M. Yaghi, Introduction to metal-organic frameworks, Chem. Rev. 112 (2012) 673-674, http://dx.doi.org/10.1021/cr300014x.

[4] H. Furukawa, K.E. Cordova, M. O'Keeffe, O.M. Yaghi, The chemistry and applications of metal-organic frameworks, Science 341 (2013) 1230444, http://dx.doi.org/ 10.1126/science.1230444.

[5] J.R. Long, O.M. Yaghi, The pervasive chemistry of metal-organic frameworks, Chem. Soc. Rev. 38 (2009) 1213, http://dx.doi.org/10.1039/b903811f.

[6] C.H. Hendon, A.J. Rieth, M.D. Korzyński, M. Dincă, Grand challenges and future opportunities for metal-organic frameworks, ACS Cent. Sci. 3 (2017) 554-563, http://dx.doi.org/10.1021/acscentsci.7b00197.

[7] G. Férey, Microporous solids: from organically templated inorganic skeletons to hybrid frameworks. ecumenism in chemistry, Chem. Mater. 13 (2001) 3084-3098, http://dx.doi.org/10.1021/cm011070n.

[8] M. Li, D. Li, M. O'Keeffe, O.M. Yaghi, Topological analysis of metal-organic frameworks with polytopic linkers and/or multiple building units and the minimal transitivity principle, Chem. Rev. 114 (2014) 1343-1370, http://dx.doi.org/10. 1021/cr400392k.

[9] D. Zhao, D.J. Timmons, D. Yuan, H.-C. Zhou, Tuning the topology and functionality of metal-organic frameworks by ligand design, Acc. Chem. Res. 44 (2011) 123-133, http://dx.doi.org/10.1021/ar100112y.

[10] B. Rungtaweevoranit, Y. Zhao, K.M. Choi, O.M. Yaghi, Cooperative effects at the interface of nanocrystalline metal-organic frameworks, Nano Res. 9 (2016) 47-58, http://dx.doi.org/10.1007/s12274-015-0970-0.

[11] M.D. Allendorf, C.A. Bauer, R.K. Bhakta, R.J.T. Houk, Luminescent metal-organic frameworks, Chem. Soc. Rev. 38 (2009) 1330, http://dx.doi.org/10.1039/ b802352m.

[12] X. Zhou, H. Li, H. Xiao, L. Li, O. Zhao, T. Yang, J. Zuo, W. Huang, A microporous luminescent europium metal-organic framework for nitro explosive sensing, Dalt. Trans. 42 (2013) 5718, http://dx.doi.org/10.1039/c3dt00055a.

[13] F.-Y. Yi, D. Chen, M.-K. Wu, L. Han, H.-L. Jiang, Chemical sensors based on metalorganic frameworks, ChemPlusChem 81 (2016) 675-690, http://dx.doi.org/10. 1002/cplu.201600137.
[14] K.D.M. Harris, M. Tremayne, B.M. Kariuki, Contemporary advances in the use of powder X-ray diffraction for structure determination, Angew. Chem. Int. Ed. 40 (2001) 1626-1651, http://dx.doi.org/10.1002/1521-3773(20010504) 40:9<1626::AID-ANIE16260 > 3.0.CO;2-7.

[15] J.H. Bang, K.S. Suslick, Applications of ultrasound to the synthesis of nanostructured materials, Adv. Mater. 22 (2010) 1039-1059, http://dx.doi.org/10.1002/ adma.200904093.

[16] W.-J. Son, J. Kim, J. Kim, W.-S. Ahn, Sonochemical synthesis of MOF-5, Chem. Commun. (2008) 6336, http://dx.doi.org/10.1039/b814740j.

[17] A. Gedanken, Using sonochemistry for the fabrication of nanomaterials, Ultrason. Sonochem. 11 (2004) 47-55, http://dx.doi.org/10.1016/j.ultsonch.2004.01.037.

[18] K.S. Suslick, S.-B. Choe, A.A. Cichowlas, M.W. Grinstaff, Sonochemical synthesis of amorphous iron, Nature 353 (1991) 414-416, http://dx.doi.org/10.1038/ $353414 \mathrm{a} 0$.

[19] Z. Hu, I. Castano, S. Wang, Y. Wang, Y. Peng, Y. Qian, C. Chi, X. Wang, D. Zhao, Modulator effects on the water-based synthesis of $\mathrm{Zr} / \mathrm{Hf}$ Metal-organic frameworks: quantitative relationship studies between modulator, synthetic condition, and performance, Cryst. Growth Des. 16 (2016) 2295-2301, http://dx.doi.org/10. 1021/acs.cgd.6b00076.

[20] A. Schaate, P. Roy, A. Godt, J. Lippke, F. Waltz, M. Wiebcke, P. Behrens, Modulated synthesis of Zr-based metal-organic frameworks: from nano to single crystals, Chem. - A Eur. J. 17 (2011) 6643-6651, http://dx.doi.org/10.1002/chem. 201003211.

[21] G. Zahn, P. Zerner, J. Lippke, F.L. Kempf, S. Lilienthal, C.A. Schröder, A.M. Schneider, P. Behrens, Insight into the mechanism of modulated syntheses: in situ synchrotron diffraction studies on the formation of Zr-fumarate MOF, CrystEngComm 16 (2014) 9198-9207, http://dx.doi.org/10.1039/C4CE01095G.

[22] K. Byrappa, M. Yoshimura, HydrothermalTechnology—Principles and Applications, in: Handb. Hydrothermal Technol., Elsevier: 2001: pp. 1-52. 〈http://dx.doi.org/10. 1016/B978-081551445-9.50002-7>.

[23] P.O. Dustan, G. Vicentini, Lanthanide(III) - diphenylphosphinates, An. Acad. Bras. Ciências. 47 (1975) 97-100.

[24] S.V. Bel'Tyukova, Luminescence and IR spectroscopy of europium(III) complexes with new organophosphorus ligands, Coord. Chem. 15 (1989) 509-513.

[25] A.P. Innocentini, E.B. Stucchi, A.M.G. Massabni, Estudo de difenilfosfinato de európio(III) como material luminescente, in: Reun. Anu. Da Soc. Bras. Química, Sociedade Brasileira de Química, Caxambú: p. 19, QM087.

[26] E.B. Stucchi, S.L. Scarpari, M.A. Couto Dos Santos, S.R. Leite, Preparation, characterization and spectroscopy of the europium diphenylphosphinate complex, J. Alloy. Compd. 275-277 (1998) 89-92, http://dx.doi.org/10.1016/S0925-8388(98) 00280-1.

[27] S.L. Scarpari, Luminescência e aspectos estruturais de difenilfosfinatos de alguns íons lantanídeos, Universidade Estadual Paulista (Unesp), 2001, 〈https:// repositorio.unesp.br/handle/11449/105811> (accessed 5 December 2017).

[28] S.L. Scarpari, E.B. Stucchi, Effects of dispersion by Gd3 + upon europium diphenylphosphinate luminescence, J. Alloy. Compd. 323-324 (2001) 740-742, http:// dx.doi.org/10.1016/S0925-8388(01)01068-4.

[29] C.S. Francisco, E.B. Stucchi, E.M. de Abreu, Luminescent properties of yttrium diphenylphosphinate activated by europium, J. Alloy. Compd. 418 (2006) 234-237, http://dx.doi.org/10.1016/j.jallcom.2005.10.067.

[30] C.S. Francisco, Complexos de lantanídeos contendo ligantes organofosforados como matrizes para materiais luminescentes, Universidade Estadual Paulista (Unesp), 2009, 〈https://repositorio.unesp.br/handle/11449/105784〉 (accessed 17 January 2018).

[31] E.M. de Abreu, Estudo dos difenilfosfinatos de lantânio ativados por cério, európio e térbio emissores luminescentes multicores, Universidade Estadual Paulista (Unesp), 2008, 〈https://repositorio.unesp.br/handle/11449/105657〉 (accessed 15 January 2018).

[32] E.M. Abreu, C.S. Francisco, S.I. Klein, E.B. Stucchi, Strongly luminescent, highly ionic europium in a lanthanum diphenylphosphinate matrix, Opt. Mater. 35 (2013) 332-337, http://dx.doi.org/10.1016/j.optmat.2012.08.003.

[33] M.L. Souza, Estudo da potencialidade dos difenilfosfinatos de lantânio dopados com $\mathrm{Ce}^{3+}$ para aplicação em protetores solares, Universidade Estadual Paulista (Unesp), 2008. 
[34] J.F.V.L. Munhoz, Estudo de difenilfosfinatos binários de lantânio(III) e cério(III) para uso em protetores solares, Universidade Estadual Paulista (Unesp), 2010.

[35] L.H.Z.R. Rosa, Estudo do efeito de cério como sensibilizador e ativador, em matrizes de difenilfosfinatos de lantânio, dopadas com európio e/ou térbio, Universidade Estadual Paulista (Unesp), 2011, 〈https://repositorio.unesp.br/handle/11449/ 132458> (accessed 15 January 2018).

[36] L.H.Z.R. Rosa, Propriedades estruturais e espectroscópicas de complexos de difenilfosfinatos dos sistemas ternários LA-CE-EU/LA-CE-TB, Universidade Estadual Paulista (Unesp), 2014, 〈https://repositorio.unesp.br/handle/11449/115643〉 (accessed 17 January 2018).

[37] L.F.B. Bim, Estrutura e algumas propriedades ópticas de difenilfosfinatos de terrasraras, Universidade Estadual Paulista (Unesp), 2015, 〈https://repositorio.unesp.br/ handle/11449/139025> (accessed 5 December 2017).

[38] D.J. Tranchemontagne, J.R. Hunt, O.M. Yaghi, Room temperature synthesis of metal-organic frameworks: MOF-5, MOF-74, MOF-177, MOF-199, and IRMOF-0, Tetrahedron 64 (2008) 8553-8557, http://dx.doi.org/10.1016/j.tet.2008.06.036.

[39] L.J. Bellamy, L. Beecher, 152. The infra-red spectra of organo-phosphorus compounds. Part III. Aliphatic acids and compounds related to natural products, J. Chem. Soc. (1953) 728, http://dx.doi.org/10.1039/jr9530000728.

[40] L. Daasch, D. Smith, Infrared spectra of phosphorus compounds, Anal. Chem. 23 (1951) 853-868, http://dx.doi.org/10.1021/ac60054a008.

[41] D. Lin-Vien, N.B. Colthup, W.G. Fateley, J.G. Grasselli, Organophosphorus Compounds, in: Handb. Infrared Raman Charact. Freq. Org. Mol., Elsevier: 1991: pp. 263-276. 〈http://dx.doi.org/10.1016/B978-0-08-057116-4.50022-5〉.

[42] E.A. Robinson, Characteristic vibrational frequencies of oxygen compounds of phosphorus and chlorine: correlation of symmetric and asymmetric stretching frequencies of PO and ClO bonds, Can. J. Chem. 41 (1963) 173-179, http://dx.doi. org/10.1139/v63-022.

[43] L.C. Thomas, R.A. Chittenden, Characteristic infra-red absorption frequencies of organophosphorus compounds-V, Spectrochim. Acta 21 (1965) 1905-1914, http://dx.doi.org/10.1016/0371-1951(65)80238-7.

[44] J.H.S.K. Monteiro, A.L.B. Formiga, F.A. Sigoli, The influence of carboxilate, phosphinate and seleninate groups on luminescent properties of lanthanides complexes, J. Lumin. 154 (2014) 22-31, http://dx.doi.org/10.1016/j.jlumin.2014.03.071.

[45] V.V. Pokropivny, V.V. Skorokhod, Classification of nanostructures by dimensionality and concept of surface forms engineering in nanomaterial science, Mater. Sci. Eng. C 27 (2007) 990-993, http://dx.doi.org/10.1016/j.msec. 2006.09.023.

[46] C. Görller-Walrand, L. Fluyt, A. Ceulemans, W.T. Carnall, Magnetic dipole transitions as standards for Judd-Ofelt parametrization in lanthanide spectra, J. Chem. Phys. 95 (1991) 3099-3106, http://dx.doi.org/10.1063/1.460867.

[47] C.K. Jørgensen, B.R. Judd, Hypersensitive pseudoquadrupole transitions in lanthanides, Mol. Phys. 8 (1964) 281-290, http://dx.doi.org/10.1080/ 00268976400100321.

[48] K. Binnemans, Interpretation of europium(III) spectra, Coord. Chem. Rev. 295 (2015) 1-45, http://dx.doi.org/10.1016/j.ccr.2015.02.015 